\title{
Review
}

\section{Gelsolin superfamily proteins: key regulators of cellular functions}

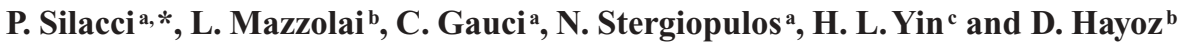 \\ a Laboratory of Hemodynamics and Cardiovascular Technology, Swiss Federal Institute of Technology, Lausanne \\ (Switzerland), Fax: +41 2169386 60, e-mail: paolo.silacci@epfl.ch \\ b Service of Angiology, University Hospital, Lausanne (Switzerland) \\ c Department of Physiology, University of Texas Southwestern Medical Center, Dallas, Texas (USA)
}

Received 28 May 2004; received after revision 29 June 2004; accepted 8 July 2004

\begin{abstract}
Cytoskeletal rearrangement occurs in a variety of cellular processes and involves a wide spectrum of proteins. Among these, the gelsolin superfamily proteins control actin organization by severing filaments, capping filament ends and nucleating actin assembly [1]. Gelsolin is the founding member of this family, which now contains at least another six members: villin, adseverin, capG, advillin, supervillin and flightless I. In addition to their respective role in actin filament remodeling, these proteins have some specific and apparently non-overlap-
\end{abstract}

ping particular roles in several cellular processes, including cell motility, control of apoptosis and regulation of phagocytosis (summarized in table 1). Evidence suggests that proteins belonging to the gelsolin superfamily may be involved in other processes, including gene expression regulation. This review will focus on some of the known functions of the gelsolin superfamily proteins, thus providing a basis for reflection on other possible and as yet incompletely understood roles for these proteins.

Key words. Gelsolin; gelsolin superfamily; cytoskeleton; apoptosis; phagocytosis; actin network.

\section{Introduction}

The gelsolin protein superfamily is a conserved family of proteins present in mammalian as well as in non-mammalian organisms. This review will focus on the role of gelsolin and gelsolin-related proteins in mammals. Gelsolin superfamily consists of seven different proteins: gelsolin, adseverin, villin, capG, advillin, supervillin and flightless I. All contain three or six homologous repeats of a domain named gelsolin-like $(\mathrm{G})$ domain (fig. 1 A). Gelsolin, a protein of $82-84 \mathrm{kDa}$, is the founding member of this family, exists as a cytoplasmic as well as a plasma isoform, and can bind, sever and cap actin filaments (reviewed in [2]). These isoforms are encoded by a single gene on chromosome $9[3,4]$. The two messenger

\footnotetext{
* Corresponding author.
}

RNAs (mRNAs) encoding cytoplasmic and plasma isoforms result from alternative splicing and use alternative transcriptional initiation sites. Gelsolin is expressed in a wide variety of cell types. Its secreted form differs from the intracellular one by a 25 -amino acid signaling peptide and the presence of a disulfide bond between cysteine residues at positions 188 and $201[3,5]$. Recent studies show that the plasma gelsolin level decreases dramatically as a result of major trauma, and that reinfusion of gelsolin can protect against lung damage associated with major burn injury and other types of insults [6-8].

Recently, a third isoform (gelsolin-3) has been described [9]. Gelsolin-3 is cytoplasmic and is characterized by 11 additional residues at the N-terminus. Gelsolin-3 is expressed in oligodendrocytes and mainly in the brain, lungs and testis [9], but its specific function is still unknown. 
Table 1. Summary of the main proven cellular functions for gelsolin superfamily proteins.

\begin{tabular}{|c|c|c|c|c|c|c|c|}
\hline & \multirow{2}{*}{$\begin{array}{l}\text { Number of } \\
\text { gelsolin- } \\
\text { like domains }\end{array}$} & \multicolumn{6}{|c|}{ Cellular functions } \\
\hline & & $\begin{array}{l}\text { Regulation of } \\
\text { actin dyna- } \\
\text { mics }\end{array}$ & Exocytosis & Cell motility & Phagocytosis & Apoptosis & $\begin{array}{l}\text { Platelet for- } \\
\text { mation and } \\
\text { activation }\end{array}$ \\
\hline Gelsolin & 6 & + & & + & $\begin{array}{l}+ \\
\text { (Fc- and integrin- } \\
\text { mediated phago- } \\
\text { cytosis) }\end{array}$ & + & + \\
\hline Adseverin & 6 & + & + & $?$ & $\begin{array}{l}+ \\
\text { (complement-me- } \\
\text { diated phagocytosis) }\end{array}$ & & + \\
\hline CapG & 3 & $\begin{array}{l}+ \\
\text { (lacks sever- } \\
\text { ing activity) }\end{array}$ & & + & & & \\
\hline Villin & 6 & + & & & & & \\
\hline Advillin & 6 & + & & & & & \\
\hline Supervillin & 6 & + & & & & & \\
\hline Flightless & 6 & + & & & & & \\
\hline
\end{tabular}

Absence of an indication means absence of studies addressing the specific role of a protein in the cellular process concerned.

$\mathbf{A}$

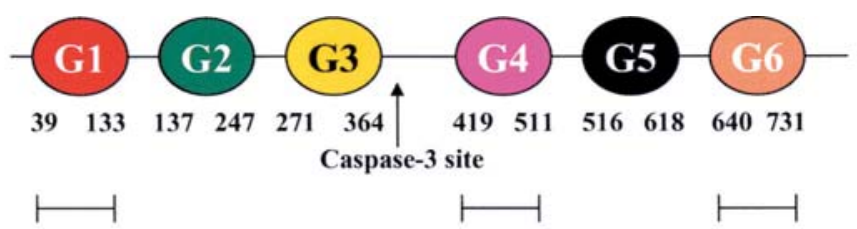

$\mathrm{Ca}^{2+}$-binding

$(-)$

B

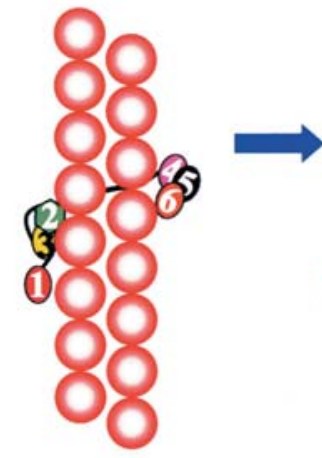

$(+)$
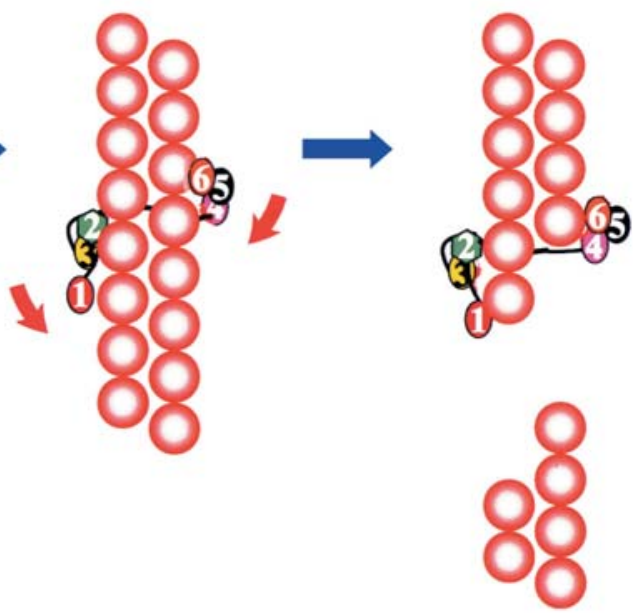

Figure 1. Schematic representation of gelsolin structure $(A)$. Residues are numbered as in human plasma gelsolin. Gelsolin can bind, sever and cap actin filaments $(B)$. Actin molecules within a filament are shown as red circles. $(+)$ and $(-)$ indicate barbed and minus ends of actin filament, respectively. After binding to actin filament, and in response to an increase in intracellular $\mathrm{Ca}^{2+}$ concentration, gelsolin undergoes a change in conformation that allows the severing process to proceed. After severing, gelsolin remains attached to the barbed end of actin filament as a cap. 
Gelsolin contains six gelsolin-like (G) domains and was first described as a protein able to bind and sever actin filaments, and to control polymerization of barbed ends. Furthermore, this protein also initiates formation of actin filaments by binding two monomeric actin molecules. Gelsolin activity is regulated by $\mathrm{Ca}^{2+}$, intracellular $\mathrm{pH}$, phosphoinositides and tyrosine phosphorylation. Crystallographic studies of gelsolin complexed with its substrate have been recently performed [10-14]. Results have been reviewed in [15] and will not be discussed here.

The other gelsolin superfamily members; villin, advillin, supervillin and flightless, have additional domains beyond the sixfold repeat. Villin has been demonstrated to participate in cytoskeleton remodeling in response to various stimuli in the intestine [16]. Flightless is the only member of gelsolin superfamily that has been shown to be essential for mouse development [17]. Among all of the proteins forming the gelsolin superfamily, adseverin (also named scinderin) is the one that shares the highest degree of homology with gelsolin. Indeed, adseverin shares $60 \%$ amino acid homology with gelsolin [18], and displays $\mathrm{Ca}^{2+}$-regulated actin filament severing activity. As compared to gelsolin, adseverin has a more restricted expression. Adseverin was first discovered in platelets, megakaryocytes and chromaffin cells [19]. This protein is present in all secretory cells and is involved in actin cytoskeleton remodeling occurring during exocytosis [19-22]. With flightless [23] and supervillin [24, 25], capG (also named gCap39, Mbh1 or macrophage capping protein) is the only other protein of gelsolin family sharing a nuclear localization [26, 27]. CapG only contains three $\mathrm{G}$ domains and can bind and cap actin filaments but cannot sever them [28]. CapG has been demonstrated to play an important role as a mediator of endothelial cell response to mechanical forces [29].

\section{Actin filament remodeling}

In the absence of $\mathrm{Ca}^{2+}$, gelsolin exists in a globular conformation. Crystal structure analysis has revealed the existence of a C-terminal tail ('latch helix') which is in close contact with the actin binding region of $\mathrm{G} 2$ domain. The importance of this latch helix in $\mathrm{Ca}^{2+}$ regulation of gelsolin-actin interactions was first revealed by the demonstration that a lack of 20 residues in the C-terminus tail abrogates the $\mathrm{Ca}^{2+}$ regulation of actin binding [30, 31]. The latch hypothesis suggests that $\mathrm{Ca}^{2+}$ binding to $\mathrm{G} 6$ domain induces a first conformational change in the gelsolin structure, releasing tail latch inhibition of G2 binding to actin. G2 binding to actin directs the G1 domain to its actin binding site. In the absence of $\mathrm{Ca}^{2+}$, G4 and G6 domains are close together. $\mathrm{Ca}^{2+}$ opens this structure, and the G6 domain forms new contacts with the G5 domain, releasing the $\mathrm{G} 4$ domain, which now can form a $\mathrm{Ca}^{2+}$ binding domain coordinated by actin and G4 itself. The actin binding sites at the $\mathrm{N}$ - and $\mathrm{C}$-terminal parts bind to two adjacent actin filaments. Slowly, gelsolin severs the two actin filaments, remaining bound to the newly formed actin + end (barbed end) of one of the two shorter filaments (fig. 1B). Further uncapping of actin filaments requires binding of gelsolin to phosphatidylinositol lipids. This process exposes the barbed end for polymerization [32, 33]. Until recently, phosphatidylinositol 3,4 or 4,5-bisphosphate (PIP2) isomers were the only known intracellular agents inhibiting gelsolin severing and inducing dissociation of gelsolin from actin. More recently, another protein of bacterial origin was shown to inhibit gelsolin severing activity. Indeed, some bacteria have the possibility to infiltrate cells delivering effector proteins that trigger a cytoskeleton rearrangement and membrane ruffling (reviewed in [34, 35]). Salmonella invasion protein a (SipA) is one of these proteins. SipA promotes actin polymerization, inducing an arrest of actin turnover. This arrest is partly exerted through inhibition of severing activity of gelsolin [36].

Additional evidence exists proving that tyrosine phosphorylation can also induce conformational change in villin and gelsolin proteins, promoting their severing activities at submicromolar concentrations of $\mathrm{Ca}^{2+}$ [37]. An additional factor that has been shown to regulate actin network reorganization via gelsolin is intracellular $\mathrm{pH}$. It has been demonstrated that the $\mathrm{Ca}^{2+}$ requirement for both severing and nucleating activities decreases with lowered $\mathrm{pH}$. Half-maximal activities require $10 \mu \mathrm{M} \mathrm{Ca}^{2+}$ at a $\mathrm{pH}$ of 7.4 and decrease to $3 \mu \mathrm{M}$ at $\mathrm{pH}$ 6.5. At low $\mathrm{pH}$ direct activation of gelsolin severing activity can also be observed in complete absence of $\mathrm{Ca}^{2+}$. This feature is not general to other gelsolin superfamily members and may be due to a conformational change of gelsolin occurring at low $\mathrm{pH}$ [38], resulting in increased association of gelsolin with actin. This increase is similar to that observed at $\mathrm{pH} 7.0$ in the presence of $\mathrm{Ca}^{2+}$. Finally, low pH-activated gelsolin can still be inhibited by PIP2.

\section{Cell motility}

Properties of the cytoskeleton depend on different parameters, such as filament length, flexibility, concentration and presence of cross-links. Proteins with the capacity to alter such properties are potentially important for regulating cellular morphology and function, as is the case for cell shape and regulation of cell motility. A first clue to evidence of the link between the expression of gelsolin or gelsolin-related proteins and cell motility was provided by transfection experiments of cultured fibroblasts [39]. Overexpression of gelsolin in these cells resulted in increased motility and concomitant inhibition of phospholipase C (PLC) $-\beta$ and $-\gamma$ [40, 41]. Surprisingly, despite 
the lack of severing activity, capG overexpression also increased fibroblast motility [42].

Gelsolin has also been shown to regulate hematopoietic stem cell motility. $\mathrm{Lin}^{-} \mathrm{Sca}^{+} \mathrm{Kit}^{+}$and $\mathrm{Lin}^{-} \mathrm{Sca}^{+} \mathrm{Kit}^{-}$, are two hematopoietic stem cell populations which show different basal and induced motility capacity. Indeed, they exhibit differential cell motility in response to stromal derived factor 1 (SDF-1), a chemokine influencing cell motility through phosphatidylinositol signaling. $\mathrm{Lin}^{-} \mathrm{Sca}^{+} \mathrm{Kit}^{+}$cells, which are more primitive than $\mathrm{Lin}^{-} \mathrm{Sca}^{+} \mathrm{Kit}^{-}$cells, exhibit a lower response in terms of cell motility, although the activation of the phosphatidylinositol pathway was activated at the same level in the two populations. Proteomics analysis documented a lower expression of gelsolin and adseverin in $\mathrm{Lin}^{-} \mathrm{Sca}^{+} \mathrm{Kit}^{+}$than in $\mathrm{Lin}^{-} \mathrm{Sca}^{+} \mathrm{Kit}^{-}$, providing an explanation for this differential response to SDF-1 [43].

CapG, which lacks severing activity, has also been shown to be involved in regulation of cellular motility in fibroblastic cells [42]. More recently, we were able to demonstrate that capG is also an important regulator of motility function in endothelial cells [29]. Endothelial cells are able to discriminate between different combinations of mechanical forces. In vivo, this capability results in a focalization of vascular areas subjected to atherosclerotic plaque development [44-46]. Indeed, plaques develop at bifurcations and curvatures which are exposed to a particular pattern of blood flow, with a low mean shear stress value and cyclic reversal of flow direction, which is in contrast with the unidirectional pattern of flow characterizing vascular areas protected against plaque development. In response to a plaque-free hemodynamic environment, capG expression and consequently endothelial motility are increased [29], resulting in a faster wound healing process [47], as compared to endothelial cells exposed to plaque-prone conditions.

In vivo evidence for gelsolin involvement in cell motility was provided by gelsolin null mice (Gsn-/-), in which motility of osteoclasts was decreased [48]. In these mice, osteoclasts were unable to form cell adhesion structures (podosomes), and therefore their basal as well as their osteopontin-induced motility was affected. Analysis of these mice identified an additional role of gelsolin in the regulation of neuronal growth, cone formation and retraction [49]. Neuronal growth cones are highly motile structures from which lamellipodia and filopodia form and retract. Formation of these structures is a $\mathrm{Ca}^{2+}$-controlled process dependent on actin cytoskeleton remodeling. In Gsn-/- mice, only retraction processes appeared to be delayed, as compared to wild-type mice, suggesting that retraction is solely dependent on the presence of gelsolin, whereas formation of filopodia is mainly dependent on adseverin activity (adseverin is indeed expressed in these cells) [49]. Finally, knockout mice revealed the essential role of capG in macrophage ruffling [50]. Indeed, macrophages rapidly change shape forming protru- sions resulting from local actin filament assembly [51], a process that is $\mathrm{Ca}^{2+}$ sensitive. In capG-/- mice, but not in Gsn-/- mice, basal and macrophage colony stimulating factor (MCSF)-induced ruffling activities were decreased [50].

\section{A further role in phagocytosis}

Phagocytosis is a complex cellular process that necessitates a continuous rearrangement of actin cytoskeleton. In polymorphonuclear leukocytes three types of phagocytosis can be distinguished: a complement-opsonized, immunoglobulin $\mathrm{G}(\mathrm{IgG})$-opsonized, and integrin-mediated phagocytosis. This latter is essential for remodeling of connective tissue. The three types of phagocytosis are mediated by three separate sets of cell surface receptors: the complement receptors (CRs), the Fcy receptors and integrin molecules [52-54]. Using Gsn-/- mice, it has been possible to demonstrate that gelsolin plays a primordial role in $\mathrm{Fc}$ receptor- and integrin- but not in complement-mediated phagocytosis [50,54-56]. Other functions associated with $\mathrm{Fc}$ receptor-mediated phagocytosis, such as the activation of NADPH-oxidase, were not affected in Gsn-/- mice [55]. An impairment of complement-opsonized phagocytosis was observed in capG/Gsn double-null mice, providing evidence for distinctive and non-overlapping functions of capG and gelsolin in phagocytic processes [50]. Finally, binding and internalization of collagen beads, a process dependent on $\alpha 2 \beta 1$ integrin [53], was also shown to be affected in Gsn-l- fibroblasts [56]. Despite the obvious need for actin cytoskeleton remodeling, allowing cells to undergo phagocytosis, details of the mechanisms relating gelsolin and capG to this process are not yet clear. Work addressing the mechanisms of regulation of actin dynamics in the context of cell migration revealed a role of gelsolin as a downstream effector of the GTP-binding protein Rac [57-59]. Once activated, Rac promotes dissociation of gelsolin and actin, allowing actin remodeling to proceed [57]. Rac activation is also a key step in Fc receptor- and integrin-mediated phagocytosis [56,60-63], and was shown to be affected in Gsn-/- fibroblasts, providing a first possible step in the mechanisms controlling phagocytosis process. Indeed, in Gsn-/- fibroblasts, activation of Rac after binding to collagen was impaired compared to wild-type fibroblasts [56]. This activation could be restored after transfection of Gsn-/- cells with gelsolin-expressing constructs and with calcium ionophores [56]. Based on these results, the authors proposed a mechanism starting from a gelsolin-mediated remodeling of actin cytoskeleton necessary for a subsequent calcium influx and Rac activation. This situation is probably more complicated because of the need of Rac for gelsolin-actin dissociation [57-59]. 


\section{Gelsolin and apoptosis}

The apoptotic process is activated through a cascade of aspartate-specific cysteine protease family named caspases. Fourteen members of this family are known in mammals and are present in the cell as precursors (zymogens). They can be divided into two main groups: the first group is activated following apoptotic stimuli and their major role is to activate downstream caspases. They are aggregated by caspase adaptor molecules (FAS-associated proteins with death domain, or Apaf-1), which promote autoactivation. The second group of caspases, the executioners (caspases$3,-6$ and -7 ), are activated by apical caspases (reviewed in $[64,65])$. Once activated, executioner caspases will cleave structural proteins and proteins involved in the repair process. One of the targets of caspase-3 is gelsolin [66]. Indeed, this enzyme cleaves gelsolin protein at $\mathrm{D}^{352}$ of the DQTD ${ }^{352} \mathrm{G}$ sequence, generating two fragments of 39 and $41 \mathrm{kDa}$. Cleaved gelsolin loses $\mathrm{Ca}^{2+}$ control of severing activity and the capacity to bind monomeric actin. Microinjection of the N-terminal gelsolin fragment (1-352), which contains the severing activity, but not of the $\mathrm{COOH}-$ terminal fragment (353-731), triggered rapid depolymerization of the actin cytoskeleton [66]. Moreover, HeLa cells that normally do not express gelsolin are rendered more susceptible to apoptosis by overexpressing gelsolin [66]. Caspases other than caspase- 3 have been suggested to be capable of cleaving gelsolin. In MCF-7 breast carcinoma cells lacking caspase-3 activity, gelsolin was still cleaved during an apoptotic process triggered by Fas antibody or tumor necrosis factor (TNF) [67]. Nevertheless, in more recent work, a possible cleavage of gelsolin by one of the two other executioner caspases ( -6 and -7 ) was excluded using a cell-free system depleted of each of these caspases. Only in the absence of caspase-3 was gelsolin not cleaved [68].

Gelsolin behaves not only as a regulator but also as an inhibitor of the apoptotic process. Initial evidences of such a dual effect of gelsolin was provided by the observation that a point mutation in mouse gelsolin confers on this protein tumor-suppressor activity against $\mathrm{H}$-ras oncogenetransformed NIH $3 \mathrm{t} 3$ cells $[69,70]$. Moreover, transfection of the gelsolin gene in a human bladder cancer cell line strongly reduced colony-forming ability and tumorigenicity in vivo [71]. More direct evidence of the inhibitory role of gelsolin was provided by Ohtsu et al., who generated Jurkat transfectants expressing up to threefold more gelsolin than wild-type cells. These transfectants exhibited a phenotype more resistant to apoptosis induced by several stimuli [72]. Different mechanisms have been proposed to explain such an inhibitory capacity. First, overexpression of gelsolin was demonstrated to prevent caspase-3 activation [72]. Second, using a cell-free system to study the apoptotic process, Azuma et al. were able to show that gelsolin can form a complex with PIP2 and cas- pase-3 to inhibit caspase-3 activity [73]. In the same work, the authors were able to demonstrate that gelsolin-PIP2 complex forms in vivo and that the formation of this complex correlates with a delay in the apoptotic process. Another hypothesis, explaining the inhibitory action of gelsolin overexpression in the apoptotic process, involves its possible action at the level of mitochondrial membrane potential. Indeed, one of the first stages of apoptosis is an increase in permeability of the mitochondrial membrane. Loss of cytochrome $\mathrm{c}$ has been linked to this loss of membrane potential $[74,75]$. When cytochrome $\mathrm{c}$ associates to the caspase-9/Apaf 1 complex, it triggers activation of an effector caspase [65]. Overexpression of gelsolin prevented this loss in mitochondrial membrane potential [76]. Gelsolin has been proposed to participate in regulation of apoptosis by binding to voltage-dependent anion channel (VDAC), the putative permeability transition pore [77]. Gelsolin-mediated protection against apoptosis is inhibited by phosphoinositides known to bind with high affinity to gelsolin, suggesting that the effect of gelsolin is due to its conformation or to its ability to bind actin [78-80]. The observation that in gelsolin-null mice neurons exhibit enhanced apoptosis due to hypoxia after a stroke further supports the hypothetic inhibitory action of gelsolin on apoptosis. In this work a protective role of gelsolin on neuronal cells in such conditions has been suggested [81].

Despite all these data, the inhibitory action of gelsolin on apoptosis remains controversial. Indeed, Posey et al. recently failed to observe a delay in Fas-induced apoptotic processes following different stimuli in $\mathrm{T}$ lymphocytes overexpressing gelsolin [82]. This discrepancy could eventually be explained by different pathways leading to apoptosis. Indeed, Fas-ligand can induce apoptosis via two mechanisms, one of which involves caspase- 8 activation, and that is independent of changes in mitochondrial membrane potential [82]. Alternatively, differences on basal and transfected gelsolin expression in the cell populations used could explain this lack of effect.

\section{Role of the gelsolin superfamily during development}

Despite the variety of processes in which gelsolin and other related proteins have been involved, Gsn-l-, capG-/- and Gsn/capG double null mice do not exhibit developmental disorders. This is probably due to the redundancy in the functions of these proteins. Mice lacking the gelsolin gene reproduce and develop normally, but adult mice exhibit some alteration in cellular processes involving cell motility. In these mice, bleeding time is increased, suggesting an alteration in platelet function, and the inflammatory process is affected because of a decreased migratory capacity of neutrophils and decreased motility of fibroblasts, resulting in slower wound healing 
[83]. Interestingly, Gsn -/- also showed some developmental alterations, such as delay in postnatal mammary gland development [84]. Ductal outgrowth was delayed until week 9 , and the mammary epithelium was unresponsive to hormone stimulation. Osteoclasts were devoid of podosomes, a cell-adhesion structure. Despite the observation that gelsolin null mice do not display any neuronal defects, alterations were observed in formation of the growth cone of neurites [49].

Analysis of gelsolin, adseverin and capG proteins during mouse development has revealed complementary expression patterns for these proteins. Gelsolin mRNA is present in multiple tissues, with the highest levels in cardiac ventricle, diaphragm and other muscles. Adseverin expression is limited to endochondral bone primordial, renal tubules and intestinal microvilli during embryogenesis. CapG is expressed in squamous epithelia, as well as specific regions of the kidney, adrenal gland and spleen and in the developing brain cortex [85]. In adult mice, adseverin expression is mainly observable in the kidney and in the intestine, and capG expression is strongly expressed in the heart, in uterus, lung, kidney and at a lower level in other tissues. Gelsolin is strongly expressed in the heart and lung, and at a lower level in skeletal muscle, kidney and testis [85].

In zebrafish, gelsolin has been shown to be specialized for high corneal expression [86], and to be required for proper dorsalization during embryogenesis [87].

Finally, fliih, the mouse homologue of Drosophila melanogaster flightless I, is the only protein belonging gelsolin superfamily family essential for normal mouse development [17]. Disruption of the fliih gene in mice results in a rapid degeneration of the embryo. Recently, flightless I was shown to function as a nuclear coactivator in response to estrogen stimulation in MCF-7 cells [23].

\section{Platelet activation}

Platelet formation and activation are processes that in volve reorganization of the actin cytoskeleton. Indeed, platelets form from megakaryocytes after proliferation, differentiation, nuclear polyploidization and apoptosis $[88,89]$. Mature megakaryocytes form long and thin cytoplasmic extensions, from which platelets are released. This process is highly related to remodeling of the actin cytoskeleton [90]. Megakaryoblastic cells express gelsolin, but not adseverin and capG [91]. Forced expression of adseverin induces megakaryoblastic cell maturation, leading to platelet formation [91]. Interestingly, expression of adseverin also causes downregulation of gelsolin expression, suggesting that adseverin may act as an apoptosis regulator in megakaryoblastic cells, while gelsolin protects megakaryoblasts from apoptosis, inhibiting their final differentiation process. These data strongly support an important role of gelsolin and related proteins in the regulation of platelet formation. Evidence exists that these proteins also play a role also in platelet activation. The first stage in this process is a change in cell shape [92], which depends on actin filament remodeling. In resting platelets actin filaments are stabilized by VASP, a cytoskeleton focal adhesion protein which shows actin binding properties. VASP protects actin filaments from the severing effects of gelsolin but does not inhibit gelsolin from binding to the filaments [93]. Moreover, resting platelets contain $\sim 2 \mu \mathrm{M} \mathrm{Cap} \mathrm{Z}$, a calcium-insensitive heterodimeric capping protein associated with the barbed ends of actin filaments [94], thus protecting barbed ends from polymerization. After stimulation, rapid severing activity of existing actin filaments is triggered [95]. This process allows amplification of barbed ends. Dissociation of gelsolin and CapZ from barbed ends, necessary for actin filament polymerization, necessitates phosphoinositide 3-kinase (PI3-kinase) activity [96]. Changes in platelet cell shape are dependent on a rise in intracellular $\mathrm{Ca}^{2+}$ and PI3-kinase activity [97, 98]. As a consequence of this remodeling process cells lose their resting discoid form in favor of an activated form with long thin filopods containing bundles of F-actin.

\section{Familial amyloidosis of the Finnish type}

Although the role of plasma gelsolin is still not completely understood, it is now known that a mutation in circulating gelsolin is the basis for a genetic disease. Indeed, association of a mutation at position 187 of the gelsolin gene with familial amyloidosis of the Finnish type (FAF) has been described [99-103]. FAF is an autosomal, dominant amyloid polyneuropathy, characterized by corneal lattice dystrophy, progressive cranial and peripheral neuropathy as well as skin changes. Mutation of Asn residue a Tyr 187 results in destabilization of the G2 domain, predicting an unfolding that will predispose gelsolin to proteolysis $[104,105]$. This aberrant cleavage generates the FAF amyloid precursor fragment of $68 \mathrm{kDa}$. Further cleavage at position 244 is required for the generation of FAF amyloid protein, which accumulates in patient tissues [106-109]. Moreover, plasma gelsolin isolated from homozygous FAF patients lacks both actin severing and nucleating activities [104]. In contrast, cytoplasmic gelsolin is not aberrantly cleaved in these patients [110], and the normal actin modulating function of intracellular gelsolin is not affected [111].

\section{Concluding remarks}

The major, intriguing observation concerning the gelsolin superfamily proteins is that despite their key role in con- 
trolling cellular processes, involving cytoskeleton remodeling, deletion of their genes in many cases is not lethal nor does it result in a clear phenotype. Processes involving cell shape changes and cell motility are slightly suppressed, but not abrogated. This apparent paradox may be explained by a compensatory mechanism by other proteins belonging to this superfamily. This observation implies that experiments affecting the expression of just one of these proteins need to be carefully interpreted. The expression of the other gelsolin superfamily proteins has to be assessed in the targeted cells and tissues. An absence of effect does not necessarily means an absence of function in vivo.

Several investigations still need to be performed in order to completely understand the function of the protein members of this family. Several aspects will need further analysis, such as the increase in nuclear capG in endothelial cells exposed to plaque-free flow [29]. In fact, the role of nuclear capG is not yet clear. It has been demonstrated that nuclear capG can interfere with nuclear PI3-kinase [112]. This may eventually suggest that capG is involved in phosphatidylinositol-driven chromatin remodeling $[113,114]$ and therefore plays a role as a general regulator of gene transcription.

A better understanding of the function of gelsolin superfamily proteins will certainly help us in comprehending cellular physiology.

Acknowledgments. We thank Dr André Mercanzini for critical reading of the manuscript. Cited works carried out by the authors of this review were supported by the Swiss National Research Foundation (grant 3200-065129.01 to P.S. and D.H.), by the National Institutes of Health (grants GM21681 and GM066110 to H.Y.) and by the Welch Foundation.

1 Yin H. L. (1987) Gelsolin: calcium- and polyphosphoinositide-regulated actin-modulating protein. Bioessays 7(4): 176179

2 Sun H. Q., Yamamoto M., Mejillano M. and Yin H. L. (1999) Gelsolin, a multifunctional actin regulatory protein. J. Biol. Chem. 274(47): 33179-33182

3 Yin H. L., Kwiatkowski D. J., Mole J. E. and Cole F. S. (1984) Structure and biosynthesis of cytoplasmic and secreted variants of gelsolin. J. Biol. Chem. 259(8): 5271-5276

4 Kwiatkowski D. J., Mehl R. and Yin H. L. (1988) Genomic organization and biosynthesis of secreted and cytoplasmic forms of gelsolin. J. Cell Biol. 106(2): 375-384

5 Wen D., Corina K., Chow E. P., Miller S., Janmey P. A. and Pepinsky R. B. (1996) The plasma and cytoplasmic forms of human gelsolin differ in disulfide structure. Biochemistry 35(30): 9700-9709

6 Rothenbach P. A., Dahl B., Schwartz J. J., O'Keefe G. E., Yamamoto M., Lee W. M. et al. (2004) Recombinant plasma gelsolin infusion attenuates burn-induced pulmonary microvascular dysfunction. J. Appl. Physiol. 96(1): 25-31

7 Christofidou-Solomidou M., Scherpereel A., Solomides C. C., Muzykantov V. R., Machtay M., Albelda S. M. et al. (2002) Changes in plasma gelsolin concentration during acute oxidant lung injury in mice. Lung 180(2): 91-104

8 Becker P. M., Kazi A. A., Wadgaonkar R., Pearse D. B., Kwiatkowski D. and Garcia J. G. (2003) Pulmonary vascular permeability and ischemic injury in gelsolin-deficient mice. Am. J. Respir. Cell Mol. Biol. 28(4): 478-484

9 Vouyiouklis D. A. and Brophy P. J. (1997) A novel gelsolin isoform expressed by oligodendrocytes in the central nervous system. J. Neurochem. 69(3): 995-1005

10 McLaughlin P. J., Gooch J. T., Mannherz H. G. and Weeds A. G. (1993) Structure of gelsolin segment 1-actin complex and the mechanism of filament severing. Nature 364(6439): 685692

11 Kiselar J. G., Janmey P. A., Almo S. C. and Chance M. R. (2003) Structural analysis of gelsolin using synchrotron protein footprinting. Mol. Cell. Proteomics 2(10): 1120-1132

12 Irobi E., Burtnick L. D., Urosev D., Narayan K. and Robinson R. C. (2003) From the first to the second domain of gelsolin: a common path on the surface of actin? FEBS Lett. 552(2-3): $86-90$

13 Narayan K., Chumnarnsilpa S., Choe H., Irobi E., Urosev D., Lindberg U. et al. (2003) Activation in isolation: exposure of the actin-binding site in the C-terminal half of gelsolin does not require actin. FEBS Lett. 552(2-3): $82-85$

14 Choe H., Burtnick L. D., Mejillano M., Yin H. L., Robinson R. C. and Choe S. (2002) The calcium activation of gelsolin: insights from the 3A structure of the G4-G6/actin complex. J. Mol. Biol. 324(4): 691-702

15 McGough A. M., Staiger C. J., Min J. K. and Simonetti K. D. (2003) The gelsolin family of actin regulatory proteins: modular structures, versatile functions. FEBS Lett. 552(2-3): 75 81

16 Ferrary E., Cohen-Tannoudji M., Pehau-Arnaudet G., Lapillonne A., Athman R., Ruiz T. et al. (1999) In vivo, villin is required for $\mathrm{Ca}(2+)$-dependent $\mathrm{F}$-actin disruption in intestinal brush borders. J. Cell Biol. 146(4): 819-830

17 Campbell H. D., Fountain S., McLennan I. S., Berven L. A., Crouch M. F., Davy D. A. et al. (2002) Fliih, a gelsolin-related cytoskeletal regulator essential for early mammalian embryonic development. Mol. Cell. Biol. 22(10): 3518-3526

18 Kwiatkowski D. J. (1999) Functions of gelsolin: motility, signaling, apoptosis, cancer. Curr. Opin. Cell Biol. 11(1): $103-$ 108

19 Rodriguez Del Castillo A., Vitale M. L., Tchakarov L. and Trifaro J. M. (1992) Human platelets contain scinderin, a Ca(2+)dependent actin filament-severing protein. Thromb. Haemost. 67(2): $248-251$

20 Tchakarov L., Vitale M. L., Jeyapragasan M., Rodriguez Del Castillo A. and Trifaro J. M. (1990) Expression of scinderin, an actin filament-severing protein, in different tissues. FEBS Lett. 268(1): 209-212

21 Vitale M. L., Rodriguez Del Castillo A., Tchakarov L. and Trifaro J. M. (1991) Cortical filamentous actin disassembly and scinderin redistribution during chromaffin cell stimulation precede exocytosis, a phenomenon not exhibited by gelsolin. J. Cell Biol. 113(5): 1057-1067

22 Marcu M. G., Zhang L., Nau-Staudt K. and Trifaro J. M. (1996) Recombinant scinderin, an F-actin severing protein, increases calcium-induced release of serotonin from permeabilized platelets, an effect blocked by two scinderin-derived actin-binding peptides and phosphatidylinositol 4,5-bisphosphate. Blood 87(1): 20-24

23 Lee Y. H., Campbell H. D. and Stallcup M. R. (2004) Developmentally essential protein flightless I is a nuclear receptor coactivator with actin binding activity. Mol. Cell. Biol. 24(5): $2103-2117$

24 Pestonjamasp K. N., Pope R. K., Wulfkuhle J. D. and Luna E. J. (1997) Supervillin (p205): a novel membrane-associated, Factin-binding protein in the villin/gelsolin superfamily. J. Cell Biol. 139(5): 1255-1269

25 Wulfkuhle J. D., Donina I. E., Stark N. H., Pope R. K., Pestonjamasp K. N., Niswonger M. L. et al. (1999) Domain analysis of supervillin, an F-actin bundling plasma membrane 
protein with functional nuclear localization signals. J. Cell Sci. 112 ( Pt 13): 2125-2136

26 Prendergast G. C. and Ziff E. B. (1991) Mbh 1: a novel gelsolin/severin-related protein which binds actin in vitro and exhibits nuclear localization in vivo. EMBO J. 10(4): 757-766

27 Onoda K., Yu F. X. and Yin H. L. (1993) gCap39 is a nuclear and cytoplasmic protein. Cell Motil. Cytoskeleton 26(3): $227-238$

28 Southwick F. S. and DiNubile M. J. (1986) Rabbit alveolar macrophages contain a $\mathrm{Ca} 2+$-sensitive, 41,000 -dalton protein which reversibly blocks the 'barbed' ends of actin filaments but does not sever them. J. Biol. Chem. 261(30): 1419114195

29 Pellieux C., Desgeorges A., Pigeon C. H., Chambaz C., Yin H., Hayoz D. et al. (2003) Cap G, a gelsolin family protein modulating protective effects of unidirectional shear stress. J. Biol. Chem. 278(31): 29136-29144

30 Kwiatkowski D. J., Janmey P. A. and Yin H. L. (1989) Identification of critical functional and regulatory domains in gelsolin. J. Cell Biol. 108(5): 1717-1726

31 Way M., Pope B., Gooch J., Hawkins M. and Weeds A. G. (1990) Identification of a region in segment 1 of gelsolin critical for actin binding. EMBO J. 9(12): 4103-4109

32 Yu F. X., Sun H. Q., Janmey P. A. and Yin H. L. (1992) Identification of a polyphosphoinositide-binding sequence in an actin monomer-binding domain of gelsolin. J. Biol. Chem. 267(21): 14616-14621

33 Liepina I., Czaplewski C., Janmey P. and Liwo A. (2003) Molecular dynamics study of a gelsolin-derived peptide binding to a lipid bilayer containing phosphatidylinositol 4,5-bisphosphate. Biopolymers 71(1): 49-70

34 Cossart P. and Sansonetti P. J. (2004) Bacterial invasion: the paradigms of enteroinvasive pathogens. Science 304(5668): $242-248$

35 Cossart P. (2004) Bacterial invasion: a new strategy to dominate cytoskeleton plasticity. Dev. Cell. 6(3): 314-315

36 McGhie E. J., Hayward R. D. and Koronakis V. (2004) Control of actin turnover by a salmonella invasion protein. Mol. Cell. 13(4): 497-510

37 Kumar N. and Khurana S. (2004) Identification of a functional switch for actin severing by cytoskeletal proteins. J. Biol. Chem.

38 Lamb J. A., Allen P. G., Tuan B. Y. and Janmey P. A. (1993) Modulation of gelsolin function. Activation at low $\mathrm{pH}$ overrides Ca2+ requirement. J. Biol. Chem. 268(12): 8999-9004

39 Cunningham C. C., Stossel T. P. and Kwiatkowski D. J. (1991) Enhanced motility in NIH 3T3 fibroblasts that overexpress gelsolin. Science 251(4998): 1233-1236

40 Sun H., Lin K. and Yin H. L. (1997) Gelsolin modulates phospholipase $\mathrm{C}$ activity in vivo through phospholipid binding. J. Cell Biol. 138(4): $811-820$

41 Banno Y., Nakashima T., Kumada T., Ebisawa K., Nonomura Y. and Nozawa Y. (1992) Effects of gelsolin on human platelet cytosolic phosphoinositide-phospholipase $\mathrm{C}$ isozymes. J. Biol. Chem. 267(10): 6488-6494

42 Sun H. Q., Kwiatkowska K., Wooten D. C. and Yin H. L. (1995) Effects of CapG overexpression on agonist-induced motility and second messenger generation. J. Cell Biol. 129(1): $147-156$

43 Evans C. A., Tonge R., Blinco D., Pierce A., Shaw J., Lu Y. et al. (2004) Comparative proteomics of primitive hematopoietic cell populations reveals differences in expression of proteins regulating motility. Blood 103(10): 3751-3759

44 Ravensbergen J., Ravensbergen J. W., Krijger J. K., Hillen B. and Hoogstraten H. W. (1998) Localizing role of hemodynamics in atherosclerosis in several human vertebrobasilar junction geometries. Arterioscler. Thromb. Vasc. Biol. 18(5): 708-716

45 Glagov S., Zarins C., Giddens D. P. and Ku D. N. (1988) Hemodynamics and atherosclerosis. Insights and perspectives gained from studies of human arteries. Arch. Pathol. Lab. Med. 112(10): 1018-1031

$46 \mathrm{Ku}$ D. N., Giddens D. P., Zarins C. K. and Glagov S. (1985) Pulsatile flow and atherosclerosis in the human carotid bifurcation. Positive correlation between plaque location and low oscillating shear stress. Arteriosclerosis 5(3): 293-302

47 Vyalov S., Langille B. L. and Gotlieb A. I. (1996) Decreased blood flow rate disrupts endothelial repair in vivo. Am. J. Pathol. 149(6): 2107-2118

48 Chellaiah M., Kizer N., Silva M., Alvarez U., Kwiatkowski D. and Hruska K. A. (2000) Gelsolin deficiency blocks podosome assembly and produces increased bone mass and strength. J. Cell Biol. 148(4): 665-678

49 Lu M., Witke W., Kwiatkowski D. J. and Kosik K. S. (1997) Delayed retraction of filopodia in gelsolin null mice. J. Cell Biol. 138(6): 1279-1287

50 Witke W., Li W., Kwiatkowski D. J. and Southwick F. S. (2001) Comparisons of CapG and gelsolin-null macrophages: demonstration of a unique role for $\mathrm{CapG}$ in receptor-mediated ruffling, phagocytosis, and vesicle rocketing. J. Cell Biol. 154(4): 775-784

51 Heidemann S. R., Kaech S., Buxbaum R. E. and Matus A. (1999) Direct observations of the mechanical behaviors of the cytoskeleton in living fibroblasts. J. Cell Biol. 145(1): 109122

52 Vidarsson G., Sigurdardottir S. T., Gudnason T., Kjartansson S., Kristinsson K. G., Ingolfsdottir G. et al. (1998) Isotypes and opsonophagocytosis of pneumococcus type 6B antibodies elicited in infants and adults by an experimental pneumococcus type 6B-tetanus toxoid vaccine. Infect. Immun. 66(6): $2866-2870$

53 Lee W., Sodek J. and McCulloch C. A. (1996) Role of integrins in regulation of collagen phagocytosis by human fibroblasts. J. Cell. Physiol. 168(3): 695-704

54 Arora P. D., Manolson M. F., Downey G. P., Sodek J. and McCulloch C. A. (2000) A novel model system for characterization of phagosomal maturation, acidification and intracellular collagen degradation in fibroblasts. J. Biol. Chem. 275(45): 35432-35441

55 Serrander L., Skarman P., Rasmussen B., Witke W., Lew D. P., Krause K. H. et al. (2000) Selective inhibition of IgG-mediated phagocytosis in gelsolin-deficient murine neutrophils. J. Immunol. 165(5): 2451-2457

56 Arora P. D., Glogauer M., Kapus A., Kwiatkowski D. J. and McCulloch C. A. (2004) Gelsolin mediates collagen phagocytosis through a rac-dependent step. Mol. Biol. Cell 15(2): $588-599$

57 Arcaro A. (1998) The small GTP-binding protein Rac promotes the dissociation of gelsolin from actin filaments in neutrophils. J. Biol. Chem. 273(2): 805-813

58 Azuma T., Witke W., Stossel T. P., Hartwig J. H. and Kwiatkowski D. J. (1998) Gelsolin is a downstream effector of rac for fibroblast motility. EMBO J. 17(5): 1362-1370

59 De Corte V., Bruyneel E., Boucherie C., Mareel M., Vandekerckhove J. and Gettemans J. (2002) Gelsolin-induced epithelial cell invasion is dependent on Ras-Rac signaling. EMBO J. 21(24): 6781-6790

60 Crowley M. T., Costello P. S., Fitzer-Attas C. J., Turner M., Meng F., Lowell C. et al. (1997) A critical role for Syk in signal transduction and phagocytosis mediated by Fcgamma receptors on macrophages. J. Exp. Med. 186(7): 1027-1039

61 Greenberg S. (1995) Signal transduction of phagocytosis. Trends Cell Biol. 5(3): 93-99

62 Caron E. and Hall A. (1998) Identification of two distinct mechanisms of phagocytosis controlled by different Rho GTPases. Science 282(5394): 1717-1721

63 Patel J. C., Hall A. and Caron E. (2002) Vav regulates activation of Rac but not Cdc42 during FcgammaR-mediated phagocytosis. Mol. Biol. Cell 13(4): 1215-1226 
64 Philchenkov A. A. (2003) Caspases as regulators of apoptosis and other cell functions. Biochemistry 68(4): 365-376

65 Green D. and Kroemer G. (1998) The central executioners of apoptosis: caspases or mitochondria? Trends Cell Biol. 8(7): 267-271

66 Kothakota S., Azuma T., Reinhard C., Klippel A., Tang J., Chu K. et al. (1997) Caspase-3-generated fragment of gelsolin: effector of morphological change in apoptosis. Science 278(5336): 294-298

67 Janicke R. U., Ng P., Sprengart M. L. and Porter A. G. (1998) Caspase- 3 is required for alpha-fodrin cleavage but dispensable for cleavage of other death substrates in apoptosis. J. Biol. Chem. 273(25): 15540-15545

68 Slee E. A., Adrain C. and Martin S. J. (2001) Executioner caspase-3, -6 and -7 perform distinct, non-redundant roles during the demolition phase of apoptosis. J. Biol. Chem. 276(10): $7320-7326$

69 Mullauer L., Fujita H., Ishizaki A. and Kuzumaki N. (1993) Tumor-suppressive function of mutated gelsolin in ras-transformed cells. Oncogene 8(9): 2531-2536

70 Fujita H., Laham L. E., Janmey P. A., Kwiatkowski D. J., Stossel T. P., Banno Y. et al. (1995) Functions of [His321]gelsolin isolated from a flat revertant of ras-transformed cells. Eur. J. Biochem. 229(3): 615-620

71 Tanaka M., Mullauer L., Ogiso Y., Fujita H., Moriya S., Furuuchi K. et al. (1995) Gelsolin: a candidate for suppressor of human bladder cancer. Cancer Res. 55(15): 3228-3232

72 Ohtsu M., Sakai N., Fujita H., Kashiwagi M., Gasa S., Shimizu S. et al. (1997) Inhibition of apoptosis by the actinregulatory protein gelsolin. EMBO J. 16(15): 4650-4656

73 Azuma T., Koths K., Flanagan L. and Kwiatkowski D. (2000) Gelsolin in complex with phosphatidylinositol 4,5-bisphosphate inhibits caspase- 3 and -9 to retard apoptotic progression. J. Biol. Chem. 275(6): 3761-3766

74 Petit P. X., Zamzami N., Vayssiere J. L., Mignotte B., Kroemer G. and Castedo M. (1997) Implication of mitochondria in apoptosis. Mol. Cell. Biochem. 174(1-2): 185-188

75 Saleh A., Srinivasula S. M., Acharya S., Fishel R. and Alnemri E. S. (1999) Cytochrome c and dATP-mediated oligomerization of Apaf-1 is a prerequisite for procaspase-9 activation. J. Biol. Chem. 274(25): 17941-17945

76 Koya R. C., Fujita H., Shimizu S., Ohtsu M., Takimoto M., Tsujimoto Y. et al. (2000) Gelsolin inhibits apoptosis by blocking mitochondrial membrane potential loss and cytochrome c release. J. Biol. Chem. 275(20): 15343-15349

77 Granville D. J. and Gottlieb R. A. (2003) The mitochondrial voltage-dependent anion channel (VDAC) as a therapeutic target for initiating cell death. Curr. Med. Chem. 10(16): $1527-1533$

78 Ahn J. S., Jang I. S., Kim D. I., Cho K. A., Park Y. H., Kim K. et al. (2003) Aging-associated increase of gelsolin for apoptosis resistance. Biochem. Biophys. Res. Commun. 312(4): $1335-1341$

79 Ahn J. S., Jang I. S., Rhim J. H., Kim K., Yeo E. J. and Park S. C. (2003) Gelsolin for senescence-associated resistance to apoptosis. Ann. N. Y. Acad. Sci. 1010: 493-495

80 Mejillano M., Yamamoto M., Rozelle A. L., Sun H. Q., Wang X. and Yin H. L. (2001) Regulation of apoptosis by phosphatidylinositol 4,5-bisphosphate inhibition of caspases, and caspase inactivation of phosphatidylinositol phosphate 5-kinases. J. Biol. Chem. 276(3): 1865-1872

81 Endres M., Fink K., Zhu J., Stagliano N. E., Bondada V., Geddes J. W. et al. (1999) Neuroprotective effects of gelsolin during murine stroke. J. Clin. Invest. 103(3): 347-354

82 Posey S. C., Martelli M. P., Azuma T., Kwiatkowski D. J. and Bierer B. E. (2000) Failure of gelsolin overexpression to regulate lymphocyte apoptosis. Blood 95(11): 3483-3488

83 Witke W., Sharpe A. H., Hartwig J. H., Azuma T., Stossel T. P and Kwiatkowski D. J. (1995) Hemostatic, inflammatory and fibroblast responses are blunted in mice lacking gelsolin. Cell 81(1): $41-51$

84 Crowley M. R., Head K. L., Kwiatkowski D. J., Asch H. L. and Asch B. B. (2000) The mouse mammary gland requires the actin-binding protein gelsolin for proper ductal morphogenesis. Dev. Biol. 225(2): 407-423

85 Arai M. and Kwiatkowski D. J. (1999) Differential developmentally regulated expression of gelsolin family members in the mouse. Dev. Dyn. 215(4): 297-307

86 Xu Y. S., Kantorow M., Davis J. and Piatigorsky J. (2000) Evidence for gelsolin as a corneal crystallin in zebrafish. J. Biol. Chem. 275(32): 24645-24652

87 Kanungo J., Kozmik Z., Swamynathan S. K. and Piatigorsky J. (2003) Gelsolin is a dorsalizing factor in zebrafish. Proc. Natl. Acad. Sci. USA 100(6): 3287-3292

88 MacPherson G. G. (1972) Origin and development of the demarcation system in megakaryocytes of rat bone marrow. $\mathrm{J}$. Ultrastruct. Res. 40(1): 167-177

89 Leven R. M. (1995) Differential regulation of integrin-mediated proplatelet formation and megakaryocyte spreading. J. Cell. Physiol. 163(3): 597-607

90 Tablin F., Castro M. and Leven R. M. (1990) Blood platelet formation in vitro. The role of the cytoskeleton in megakaryocyte fragmentation. J. Cell Sci. 97 (Pt 1): 59-70

91 Zunino R., Li Q., Rose S. D., Romero-Benitez M. M., Lejen T., Brandan N. C. et al. (2001) Expression of scinderin in megakaryoblastic leukemia cells induces differentiation, maturation and apoptosis with release of plateletlike particles and inhibits proliferation and tumorigenesis. Blood 98(7): 2210-2219

92 Casella J. F., Flanagan M. D. and Lin S. (1981) Cytochalasin $\mathrm{D}$ inhibits actin polymerization and induces depolymerization of actin filaments formed during platelet shape change. Nature 293(5830): 302-305

93 Bearer E. L., Prakash J. M., Manchester R. D. and Allen P. G. (2000) VASP protects actin filaments from gelsolin: an in vitro study with implications for platelet actin reorganizations. Cell Motil. Cytoskeleton 47(4): 351-364

94 Nachmias V. T., Golla R., Casella J. F. and Barron-Casella E. (1996) Cap Z, a calcium insensitive capping protein in resting and activated platelets. FEBS Lett. 378(3): 258-262

95 Hartwig J. H. (1992) Mechanisms of actin rearrangements mediating platelet activation. J. Cell Biol. 118(6): 1421-1442

96 Barkalow K., Witke W., Kwiatkowski D. J. and Hartwig J. H. (1996) Coordinated regulation of platelet actin filament barbed ends by gelsolin and capping protein. J. Cell Biol. 134(2): 389-399

97 Falet H., Barkalow K. L., Pivniouk V. I., Barnes M. J., Geha R. S. and Hartwig J. H. (2000) Roles of SLP-76, phosphoinositide 3-kinase and gelsolin in the platelet shape changes initiated by the collagen receptor GPVI/FcR gamma-chain complex. Blood 96(12): 3786-3792

98 Barkalow K. L., Falet H., Italiano J. E. Jr, van Vugt A., Carpenter C. L., Schreiber A. D. et al. (2003) Role for phosphoinositide 3-kinase in Fc gamma RIIA-induced platelet shape change. Am. J. Physiol. Cell Physiol. 285(4): C797-805

99 Maury C. P., Alli K. and Baumann M. (1990) Finnish hereditary amyloidosis. Amino acid sequence homology between the amyloid fibril protein and human plasma gelsoline. FEBS Lett. 260(1): $85-87$

100 Maury C. P. and Baumann M. (1990) Isolation and characterization of cardiac amyloid in familial amyloid polyneuropathy type IV (Finnish): relation of the amyloid protein to variant gelsolin. Biochim. Biophys. Acta 1096(1): 84-86

101 Ghiso J., Haltia M., Prelli F., Novello J. and Frangione B. (1990) Gelsolin variant (Asn-187) in familial amyloidosis, Finnish type. Biochem. J. 272(3): 827-830

102 de la Chapelle A., Kere J., Sack G. H. Jr, Tolvanen R. and Maury C. P. (1992) Familial amyloidosis, Finnish type: G654 
- a mutation of the gelsolin gene in Finnish families and an unrelated American family. Genomics 13(3): 898-901

103 de la Chapelle A., Tolvanen R., Boysen G., Santavy J., Bleeker-Wagemakers L., Maury C. P. et al. (1992) Gelsolinderived familial amyloidosis caused by asparagine or tyrosine substitution for aspartic acid at residue 187. Nat. Genet. 2(2): $157-160$

104 Weeds A. G., Gooch J., McLaughlin P. and Maury C. P. (1993) Variant plasma gelsolin responsible for familial amyloidosis (Finnish type) has defective actin severing activity. FEBS Lett. 335(1): 119-123

105 Isaacson R. L., Weeds A. G. and Fersht A. R. (1999) Equilibria and kinetics of folding of gelsolin domain 2 and mutants involved in familial amyloidosis-Finnish type. Proc. Natl. Acad. Sci. USA 96(20): 11247-11252

106 Maury C. P., Kere J., Tolvanen R. and de la Chapelle A. (1990) Finnish hereditary amyloidosis is caused by a single nucleotide substitution in the gelsolin gene. FEBS Lett. 276(1-2): 75-77

107 Haltia M., Prelli F., Ghiso J., Kiuru S., Somer H., Palo J. et al. (1990) Amyloid protein in familial amyloidosis (Finnish type) is homologous to gelsolin, an actin-binding protein. Biochem. Biophys. Res. Commun. 167(3): 927-932

108 Paunio T., Kangas H., Kalkkinen N., Haltia M., Palo J. and Peltonen L. (1994) Toward understanding the pathogenic mechanisms in gelsolin-related amyloidosis: in vitro expres- sion reveals an abnormal gelsolin fragment. Hum. Mol Genet. 3(12): 2223-2229

109 Paunio T., Kangas H., Heinonen O., Buc-Caron M. H., Robert J. J., Kaasinen S. et al. (1998) Cells of the neuronal lineage play a major role in the generation of amyloid precursor fragments in gelsolin-related amyloidosis. J. Biol. Chem. 273(26): 16319-16324

110 Kangas H., Paunio T., Kalkkinen N., Jalanko A. and Peltonen L. (1996) In vitro expression analysis shows that the secretory form of gelsolin is the sole source of amyloid in gelsolin-related amyloidosis. Hum. Mol. Genet. 5(9): 1237-1243

111 Kangas H., Ulmanen I., Paunio T., Kwiatkowski D. J., Lehtovirta M., Jalanko A. et al. (1999) Functional consequences of amyloidosis mutation for gelsolin polypeptide analysis of gelsolin-actin interaction and gelsolin processing in gelsolin knock-out fibroblasts. FEBS Lett. 454(3): 233239

112 Lu P. J., Hsu A. L., Wang D. S., Yan H. Y., Yin H. L. and Chen C. S. (1998) Phosphoinositide 3-kinase in rat liver nuclei. Biochemistry 37(16): $5738-5745$

113 Steger D. J., Haswell E. S., Miller A. L., Wente S. R. and O'Shea E. K. (2003) Regulation of chromatin remodeling by inositol polyphosphates. Science 299(5603): 114-116

114 Rando O. J., Chi T. H. and Crabtree G. R. (2003) Second messenger control of chromatin remodeling. Nat. Struct. Biol. 10(2): $81-83$.

\section{(7) To access this journal online: (48) http://www.birkhauser.ch}

